\title{
Exactitud diagnóstica de la oscilometría de impulso en niños preescolares con asma
}

Elida Dueñas-Meza, Diana Carolina Duarte, Carlos Eduardo Aguirre-Franco, Luis Fernando Giraldo-Cadavid

Fundación Neumológica Colombiana

\section{Introducción}

Las pruebas de función pulmonar pueden contribuir a objetivar el diagnóstico de asma en los niños. El objetivo de este estudio es estimar la exactitud diagnóstica de la oscilometria de impulso (IOS) para asma usando los criterios de GINA (Global Strategy for Asthma Management and Prevention) y el indice predictivo de asma (IPA) como referencia (gold standard).

\section{Métodos}

Estudio de prueba diagnóstica de corte transversal Fueron incluidos niños entre 3 y 6 años de la Fundación Neumológica Colombiana, con sintomas respiratorios crónicos sugestivos de asma por al menos un año. Se realizó un test de IOS (Jaeger MasterScreen(B)) teniendo en cuenta las recomendaciones de la ATS/ERS. Los valores de la resistencia (Rrs) y la reactancia (Xrs) de las vias aéreas fueron calculados en un periodo de tiempo de $30 \mathrm{~s}$ con un rango de frecuencia de $5-20 \mathrm{~Hz}$; Rrs5, Rrs20, Xrs5, Fres, y AX. Se construyeron curvas ROC con los datos obtenidos, y se estableció un punto de corte para el diagnóstico de asma. Los valores de la IOS fueron comparados con los valores de referencia de niños sanos de la misma institución. Se utilizó la prueba $U$ de Mann-Whitney $U$ y se formularon hipótesis a dos colas con un nivel de significación $<0.05$
134 pacientes, Resultados

$53.7 \%$ masculino. $537 \%$ fueron IPA-positivo para el diagnóstico de asma Rrs5, Rrs20 y el porcentaje de respuesta postbroncodilatador fue significativa en pacientes asmáticos $(P<0.05)$, sin capacidad discriminatoria entre niños asmáticos y no-asmáticos (área bajo la curva ROC [AUC$R O C]<0.6)$ (Figura 1). Solo la Xrs5 mostró una diferencia significativa aceptable AUC-ROC (AUC-ROC: 0.7 ; IC $95 \%$ :0.62-0.78\%; $P<0.001$ ), con un punto de corte de $\geq 3.55$ (Youden's Index) con la mejor capacidad discriminatoria la sensibilidad fue de $55 \%$, especificidad $81.1 \%$. Comparando los valores de la IOS en pacientes asmáticos con los niños sanos, la Xrs5, Rrs20 y el porcentaje de cambio de la Xrs5 and Rrs20 fueron significativamente diferentes. La Xrs5 y el porcentaje de cambio de la Rrs20 fueron las variables con mejor capacidad discriminatoria para diferenciar los pacientes asmáticos de los sanos $(\mathrm{P}<$ $0.001, P: 0.035$ ) (Figura 2).

\section{Resultados} Figura 1. Curva ROC para variables predictivas de la
oscilometria de impulse (IOS) vs GINA

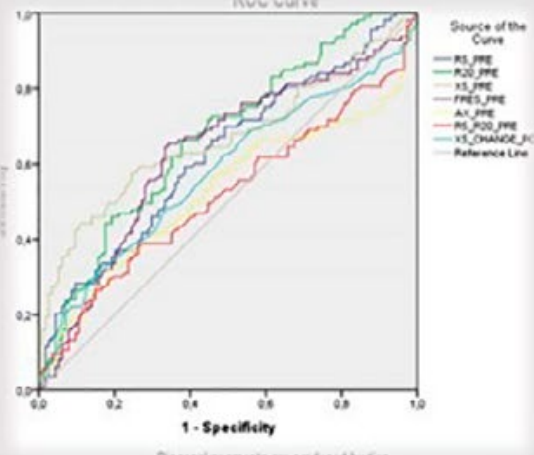

Figura 2. Curva ROC para variables predictivas de la oscilometria de impulse (IOS) vs indice predictivo de asma (IPA)

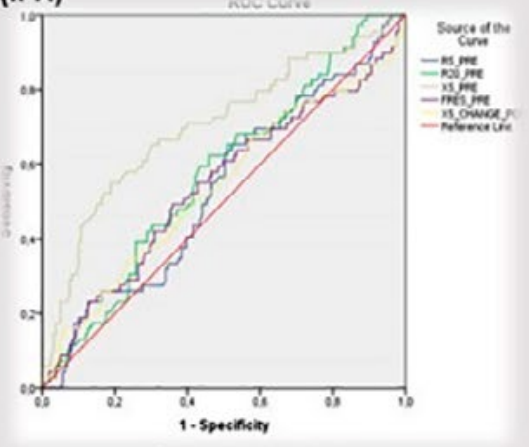

\section{Conclusiones}

La capacidad discriminatoria de la IOS para el diagnóstico de asma en niños preescolares es débil. Sin embargo, algunas variables, como la Xrs5, pueden contribuir al diagnóstico de asma a pesar de su baja sensibilidad y especificidad. El diagnóstico de asma en niños preescolares sigue siendo complejo y basado principalmente en el criterio clinico. 